\title{
Guest editorial: Reforming Home Care in Ageing Societies
}

\author{
Tine Rostgaard PhD ${ }^{1}$, Virpi Timonen BA, MPhil, DPhil ${ }^{2}$ and Caroline Glendinning DipComWk, BA (Hons), MPhil ${ }^{3}$ \\ ${ }^{1}$ Aalborg University, Aalborg, Denmark, ${ }^{2}$ School of Social Work and Social Policy, Trinity College Dublin, Dublin, Ireland \\ and ${ }^{3}$ Social Policy Research Unit, University of York, York, UK
}

In the context of ageing societies, the importance of home-based care is growing in all OECD countries. Home care is widely considered to be a financially sustainable way of supporting the independence and accommodating the preferences of older and disabled people; demand for home based care and support is likely to increase in the future. The number and share of the population aged 80+ will continue to grow in all developed countries and, despite the fact that disability prevalence rates have declined in some countries, greater longevity is likely to lead to an increasing number of people at older ages with severe disabilities and need for long-term care (Lafortune \& Balestat 2007). With falling rates of institutional living, growing numbers will rely on home care services; this also means that home care services will have to adapt to coping with higher levels of disability among their users (Jacobzone et al. 1999).

The cost of long-term care for people aged 65 and over is expected to rise from the current level of $1 \%$ of GDP across OECD countries to between $2 \%$ and $4 \%$ of GDP by 2050 (Oliveira Martins \& De La Maisonneuve 2006). When people under 65 are included, public spending on health and long-term care could rise from the current average level of $6-7 \%$ of GDP to around $10 \%$ by 2050 (Oliveira Martins \& De La Maisonneuve 2006). Societal changes add further pressures for new care solutions. These include increasing female labour market participation, postponement of the retirement age for the workforce in general, changing family forms and in, some countries, changes in attitudes as to who bears responsibility for providing care for older and disabled people.

Most countries also face difficulties in attracting and retaining care workers to what is often perceived to be physically and mentally demanding work. Strategies to reduce demand for long-term care workers include the increasing use of information and communication technologies; improved co-ordination between the long-term care and health care sectors; promotion of healthy ageing policies and self-care; and redefining job tasks so that less qualified assistants can carry out simpler care tasks (Fujisawa \& Columbo 2009). Some countries have sought to address a shortage of long-term care workers by employing migrant workers in the formal care sector, or by facilitating the private employment of migrant care workers in the home (Simonazzi 2009). Concerns have been raised about both the quality of such care and the working conditions of these carers (e.g. Doyle \& Timonen 2010). Strategies to overcome shortages of care workers have in many countries been underpinned by the introduction of cash-for-care allowances, although these are often also intended to facilitate choice by users between different sources of care (Timonen et al. 2006, Burau et al. 2007). These strategies have further contributed to the marketization of care, accompanied by a growing trend towards 'New Public Management' (NPM) market inspired reforms.

How various countries have responded to growing needs for home care, the challenges encountered in the course of reform and the relative success of different reform strategies are the focus of this special issue of Health and Social Care in the Community. The special issue documents the responses of nine European countries (Finland, Sweden, Norway, Denmark, Germany, Austria, Italy, England and Ireland) to the challenges of providing greater volumes and intensity of home-based care for older and disabled people. All but two of the papers are based on LIVINDHOME, a collaborative research project on reforms in European home care for older and disabled people which was jointly commissioned in January 2010 by the French Mission Recherche (MiRe) of the Direction de la Recherche, des études, de l'évaluation et des statistiques, Ministere de la Santé (DREES) and the National Solidarity Fund for Autonomy (CNSA - Caisse Nationale de Solidarité pour l'Autonomie). (More information on the study can be found at: http:/www.sfi.dk/LIVINDHOME). In this special issue, collaborators to the study have been joined by colleagues from the Netherlands and France, who have addressed the same research questions. We want to thank the Nordic Centre of Excellence REASSESS for financing the language editing of all the articles.

The aim of the LIVINDHOME project was to identify and compare how European countries have reformed their home help systems in the search for (1) high quality care which meets increasingly diversified and individualized needs; (2) efficient and effective provision mechanisms that facilitate cost containment; (3) a stronger user-orientation in the provision of care; (4) an optimal balance between formal and informal sources of care; 
and (5) the best way to attract and retain home care workers. Different countries have adopted different approaches to achieving and reconciling these aims; this special issue provides timely analysis of how they have done so, and with what effects.

Together, the contributions to this special issue show that new governance mechanisms have been introduced in all of the countries, accompanied by targeting and decentralisation processes and by shifting divisions of work in the mixed welfare economy. Modernisation of the modalities of organisation and governance of home care systems is evident in all countries, although unique political, historical and cultural contexts shape each country's approach, as do the different configurations of key actors, such as providers, users and public authorities. Thus countries differ in the division of competencies and responsibilities between different levels of government; in the types of entitlement that govern access to care; and in the ways in which the delivery of home care services are organised. However, many questions remain unanswered, including how the process of modernisation has affected the quality of the care and the conditions under which both employed workers and family members provide care; and the longer-term sustainability of reformed arrangements. The contributions to this special issue all focus on identifying the drivers of change and countries' responses to these, with regard to the organisation, provision, regulation and quality of home care. Each article analyses national policies and experiences of reforming home care for older and disabled people, and identifies some of the resulting tensions that characterize the country in question.

The first contribution from Barbara da Roit outlines the tensions between guaranteeing access to good quality home care while at the same time controlling costs in a universal system such as the Netherlands. Although home care in the Netherlands was initially promoted as a less costly alternative to institutional care, in recent years a cost-containment discourse has dominated in home care itself, stimulating new debates about where overall responsibility for longterm care risks lies, levels of resources and regulation of the home care system.

This is followed by an article on the French home care system, by Blanche Le Bihan. The article investigates the impact of introducing a cash-for-care scheme as part of a seemingly contradictory French public strategy, to strengthen the formal professional care sector while at the same time encouraging the development of new forms of informal care. The author finds that although a process of formalization has taken place in France which has recognized care as work, care has nevertheless not become more professionalized. Care work still is dominantly provided by informal and semi-formal carers.
Tine Rostgaard in her article investigates the reform strategies in the Danish home help system. Recent reforms have attempted to improve the overall quality of care by introducing more transparency at the political, administrative and user levels. However, reforms have revolved around the conflicting principles of standardisation and individualisation of care provision and have mainly succeeded in increasing political and administrative control over home care services, at the expense of users, care workers and case managers.

Cristiano Gori discusses the development of Italian home care which, contrary to most expectations, has not involved the expansion of services in kind but instead has relied instead on national and regional cash-for-care schemes. He argues that the main reason for this development is the fragmented politics of social care at a national level and anticipates that Italian politicians will in the near future face the urgent task of considering how to improve quality of care, carers' employment conditions and support for users with high level needs.

August Österle and Gudrun Bauer, in discussing the Austrian home care system, analyse the combined impact of a traditional family orientation to care, a universal cash-for-care scheme and a growing migrant care sector. They demonstrate that, despite this combination of apparently unfavourable factors, Austria has seen a substantial increase in the volume of formal home care services over the past two decades, driven by clients and their increased purchasing power. However, these developments may be threatened by budgetary constraints in the near future.

The introduction of long-term care insurance in Germany established a universal social right to support by older and younger disabled people with care needs. Hildegard Theobald looks at how this restructuring of formal care entitlements interplays with informal, family care. She finds that despite the new social rights for users of care (and to a lesser extent for family carers), the employment conditions and wages of paid care workers have worsened, especially care workers in the grey market or those offering 24-hour domestic care services.

Mia Vabø's article on reforms in the Norwegian home care system investigates how a system otherwise characterised by collegiality and flexible organization has been challenged by new modes of governance introduced under the banner of transparency and accountability, although often with the purpose of containing costs. She argues that these new governance arrangements have created a system which is less sensitive to the particular needs of individual service recipients and have disempowered the very people who they were intended to benefit.

The purchaser-provider split has become an entrenched feature of home care in England, extending 
from local authorities purchasing on behalf of users to the expectation that individuals will increasingly exercise choice through their own purchase of care and support. Caroline Glendinning argues that this in turn may lead to a more diverse workforce as care recipients elect to hire their own care workers rather than receiving services from organised service providers. However, any benefits of enhanced user choice are seriously threatened by the increasing emphasis on cost-containment; the exclusion of all but those with the very highest support needs from access to publicly-funded home care; and the low levels of provision, especially for older people, who do qualify.

Sweden has moved from a home care model that combined universalism and individualised services towards one where access has become more tightly needs-tested and services have become marketised. Marta Szebehely and Gun-Britt Trydegård explore the factors driving these trends. They argue that they are mainly the result of cost-containment policies by municipalities and of the promotion of markets by national policy makers. Some of the consequences of these pressures are the growing contributions made by some (predominantly lower income) families to the care of older and disabled relatives; and an increase in privately purchased services by the better-off.

Ireland has moved rapidly from a system where home care was exclusively the domain of families and non-profit providers, to a complex care mix that incorporates public, private and non-profit providers. Virpi Timonen, Martha Doyle and Ciara O'Dwyer show that providers continue to operate in the absence of a regulatory framework and the basis of entitlement to home care remains loosely defined; these features are the result of an equivocal approach by the state to home care as a new public policy issue.

Finally, Teppo Kröger and Anu Leinonen in their article describe how extensive changes in Finnish home care systems have been implemented over the last two decades, despite the absence of any explicit, stated reforms. There are two main components to this change: the restriction of formal home care services to those with the highest level of personal care needs; and the extension of support for informal carers. As a result, formal home care is now more difficult to qualify for, is largely limited to meeting personal care needs and has come to substitute for institutional care in many cases. Overall, these changes represent a weakening of defamilisation, in that responsibility for caring for frail elderly and disabled is increasingly left to the family.

\section{References}

Burau V., Theobald H. \& Blank R. (2007) Governing Home Care: A Cross-National Comparison. Edward Elgar, Heltenham.

Doyle M. \& Timonen V. (2010) Caring and collaborating across cultures? Migrant care workers' relationships with care recipients, colleagues and employers. European Journal of Women's Studies 17 (1), 25-41.

Fujisawa R. \& Columbo F. (2009) The Long-Term Care Workforce: Overview and Strategies to Adapt Supply to a Growing Demand. OECD Health Working Papers, No. 44. OECD, Paris.

Jacobzone S., Cambois E., Chaplain E. \& Robine J.M. (1999) The Health of Older Persons in OECD Countries: Is it Improving Fast Enough to Compensate for Population Ageing? Labour Market and Social Policy, Occasional Paper no. 37. OECD, Paris.

Lafortune G. \& Balestat G. (2007) Trends in Severe Disability Among Elderly People: Assessing the Evidence in 12 OECD Countries and the Future Implications. OECD Health Working Papers no. 26. OECD, Paris.

Oliveira Martins M. J. \& De La Maisonneuve C. (2006) The Drivers of Public Expenditure on Health and Long-Term Care: An Integrated Approach. OECD Economic Studies no. 43. OECD, Paris.

Simonazzi A. (2009) Care regimes and national employment models. Cambridge Journal of Economics 33 (2), 211232.

Timonen V., Convery J. \& Cahill S. (2006) Care revolutions in the making? A comparison of cash-for-care programmes in four European countries. Ageing and Society 26 (3), 455-474. 